\title{
The Trade-Off Between Chicken Welfare and Public Health Risks in Poultry Husbandry: Significance of Moral Convictions
}

\author{
M. van Asselt ${ }^{1,2}$ (D) E. D. Ekkel ${ }^{3} \cdot$ B. Kemp ${ }^{2}$ E. N. Stassen ${ }^{2}$
}

Accepted: 19 April 2019 / Published online: 2 May 2019

(c) The Author(s) 2019

\begin{abstract}
Welfare-friendly outdoor poultry husbandry systems are associated with potentially higher public health risks for certain hazards, which results in a dilemma: whether to choose a system that improves chicken welfare or a system that reduces these public health risks. We studied the views of citizens and poultry farmers on judging the dilemma, relevant moral convictions and moral arguments in a practical context. By means of an online questionnaire, citizens $(n=2259)$ and poultry farmers $(n=100)$ judged three practical cases, which illustrate the dilemma of improving chicken welfare or reducing public health risks for Campylobacter, avian influenza and dioxin. Furthermore, they scored the importance of moral arguments and to what extend they agreed with moral convictions related to humans and chickens. Citizens were more likely than farmers to choose a system that benefits chicken welfare at the expense of public health. These different judgments could be explained by differing moral convictions and valuations of moral arguments. Judgments of citizens and farmers were associated with moral arguments and convictions, predominantly with those regarding the value of chickens and naturalness. Citizens agreed stronger with moral convictions regarding the intrinsic value of chickens and regarding naturalness than farmers did, while farmers agreed stronger with conviction regarding fairness. We argue that opinions of citizens and farmers are context-dependent, which may explain the differences between these groups. It implies that opinions of different stakeholder groups should be considered in order to achieve successful innovations in poultry husbandry, which are supported by society.
\end{abstract}

Keywords Animal welfare - Moral convictions - Poultry husbandry · Public health · Stakeholder views

M. van Asselt

m.van.asselt@aeres.nl

Extended author information available on the last page of the article 


\section{Introduction}

In intensive poultry husbandry systems, which were introduced after World War II, large numbers of chickens are kept at high stocking densities in order to produce ample and affordable poultry products efficiently (Rollin 2004). The drawbacks of these intensive indoor systems with the focus on high production are animal welfare issues, such as production-related diseases and behavioural problems. These welfare issues in the intensive systems led to societal concerns regarding poultry husbandry, which focused on chickens' opportunities to express natural behaviour and lead natural lives (Eurobarometer 2005; Fraser et al. 1997; McGlone 2001; Rollin 2007). Consequently, the general public, led by NGO campaigns, called for alternative husbandry systems for chickens that are more animal welfare-friendly, offering animals more space and freedom to express natural behaviour, e.g. by means of outdoor husbandry systems.

The more welfare-friendly poultry husbandry systems, however, are associated with higher public health risks for certain hazards, such as Campylobacter, avian influenza, and dioxin. For example, for broiler chickens, outdoor access and an older age at slaughter are risk factors for an increased Campylobacter prevalence in broilers and on broiler meat (Bouwknegt et al. 2004; EFSA 2011; Sommer et al. 2013). Outdoor access for laying hens increases the risk of introducing avian influenza into a flock (Gonzales et al. 2013; Koch and Elbers 2006) and of elevated dioxin levels in eggs (EFSA 2012; Schoeters and Hoogenboom 2006) relative to indoor systems. These examples show that adaptations in husbandry systems in order to improve chicken welfare, such as outdoor access, may be a risk to public health. They imply that the choice for husbandry systems, in particular for indoor or outdoor systems, causes dilemmas necessitating choices between chicken welfare and certain public health and food safety risks. The question is how people-both the general public and poultry farmers-balance the interests of chickens against those of humans when faced with the dilemma of choosing a system that improves chicken welfare or reduces public health and food safety risks. An understanding of how to achieve this balance and approach the dilemma is useful for developing or adapting husbandry systems in such way that they can count on support from society.

At the farm level, the dilemma of improving chicken welfare or reducing public health risks in poultry husbandry is influenced by many factors, such as scientific facts, fundamental moral values and convictions considering humans and animals. Fundamental moral values are deeply rooted beliefs that are founded on knowledge, and multiple social, cultural, and religious aspects, and are shared in society (Beauchamp and Childress 2009; Cohen et al. 2009). In individuals or in a group of individuals, such as farmers, these fundamental moral values are influenced by knowledge, personal experiences with animals, and belief in mental capacity of animals (Knight and Barnett 2008; Knight et al. 2009), and become personal moral convictions regarding animals and animal husbandry. In a society or in a specific group, people may share moral convictions concerning humans and animals. For example, in the Netherlands most people consider animals to have intrinsic value, and $67 \%$ of people consider humans to be superior to animals (Cohen et al. 2012). In a practical 
case, however, moral convictions are shaped to the specific context and the entities involved, and are balanced against each other and relevant facts (Childress et al. 2002; Cohen et al. 2009; Cohen and Stassen 2016). It may result in people making different judgments regarding the dilemma of improving chicken welfare or reducing public health risks.

Previous studies have shown that citizens and farmers have different views on (1) the preferred husbandry systems for laying hens and broiler chickens (Stadig et al. 2015, 2016; Van Asselt et al. 2015); and (2) the importance of various issues such as animal welfare and public health risks (Stadig et al. 2015; Van Asselt et al. 2015; Vanhonacker et al. 2008, 2016). For poultry husbandry, it has been shown that compared to poultry farmers, citizens have more positive views regarding outdoor poultry husbandry systems (Van Asselt et al. 2015; Vanhonacker et al. 2016). Moreover, citizens evaluate chicken welfare in outdoor systems as better (Van Asselt et al. 2017; Vanhonacker et al. 2016), and certain public health hazards in outdoor systems as less risky than do poultry farmers (Van Asselt et al. 2018). These different views of poultry farmers and citizens on poultry husbandry systems may be based on different moral convictions related to humans and chickens. It is expected that citizens and poultry farmers will make different judgments regarding a dilemma of improving chicken welfare or reducing public health risks, because they may have different views on the importance of various moral arguments related to their moral convictions. As yet, no studies have compared citizens' and farmers' judgments regarding a dilemma of improving chicken welfare or reducing public health risks, and moral convictions and arguments involved. Therefore, the objective of this study is to fill this knowledge gap.

To study dilemmas in society and the moral convictions involved, multi-criteria frameworks have been developed which integrate values from the consequentialist and deontological perspectives. These frameworks give insight into various moral convictions and arguments regarding fundamental moral values such as autonomy, justice, and wellbeing for different interest groups, such as farmers, consumers, and animals (Beauchamp and Childress 2009; Mepham 2000). Other researchers have elaborated further on these frameworks and adapted them in order to study moral convictions and arguments regarding humans and animals in a specific context, such as livestock husbandry or food production (e.g. Bergstra et al. 2015; Bruijnis et al. 2015; Cohen et al. 2009; Gremmen et al. 2018; Jensen et al. 2011; Mepham 2000; Michalopoulos et al. 2008). These frameworks, however, are not specific to the dilemmas of improving chicken welfare or reducing public health risks and do not cover the debates on these dilemmas. To study the judgments of the dilemma, and relevant moral convictions and arguments of citizens and poultry farmers, existing frameworks should be adapted in order to develop a framework that considers moral convictions and arguments specifically for the dilemma presented.

To study the judgment of the dilemma, three practical cases were used. For the cases, three potential public health risks were chosen which may arise more often in alternative and outdoor poultry husbandry systems than in conventional indoor husbandry systems: (1) Campylobacter in broilers; (2) avian influenza introduction in laying hens; and (3) dioxin in eggs. The objective of this paper is to compare 
citizens' and poultry farmers' views on (1) moral convictions regarding humans and chickens; (2) the judgment of the dilemma of improving chicken welfare or reducing public health risks; and (3) the valuation of moral arguments relevant for the judgment of three practical cases representing the dilemma.

\section{Materials and Methods}

To study the judgment of three cases illustrating the dilemma, moral arguments, and moral convictions relevant for citizens and poultry farmers, a survey was carried out by means of an online questionnaire. Three cases were selected which represent a dilemma of choosing a system that improves chicken welfare or reduces the public health or food safety risk for Campylobacter, avian influenza or dioxin. These cases were selected because the public health or food safety hazard may occur more often in alternative and outdoor husbandry systems than in conventional indoor systems. The questionnaire was based on a multi-criteria framework containing moral convictions, moral arguments, and the three cases describing a dilemma.

\section{Framework}

The multi-criteria framework (Fig. 1) is based on an analysis of existing frameworks regarding dilemmas in animal and food production, and an analysis of the debate related to chicken welfare and public health risks (e.g. Bergstra et al. 2015; Bruijnis et al. 2015; Cohen et al. 2009; Gremmen et al. 2018; Jensen et al. 2011; Mepham 2000; Michalopoulos et al. 2008). Because our study focuses on the dilemma of choosing a system that improves chicken welfare or reduces public health risks related to poultry farming, only convictions directly relevant for this dilemma
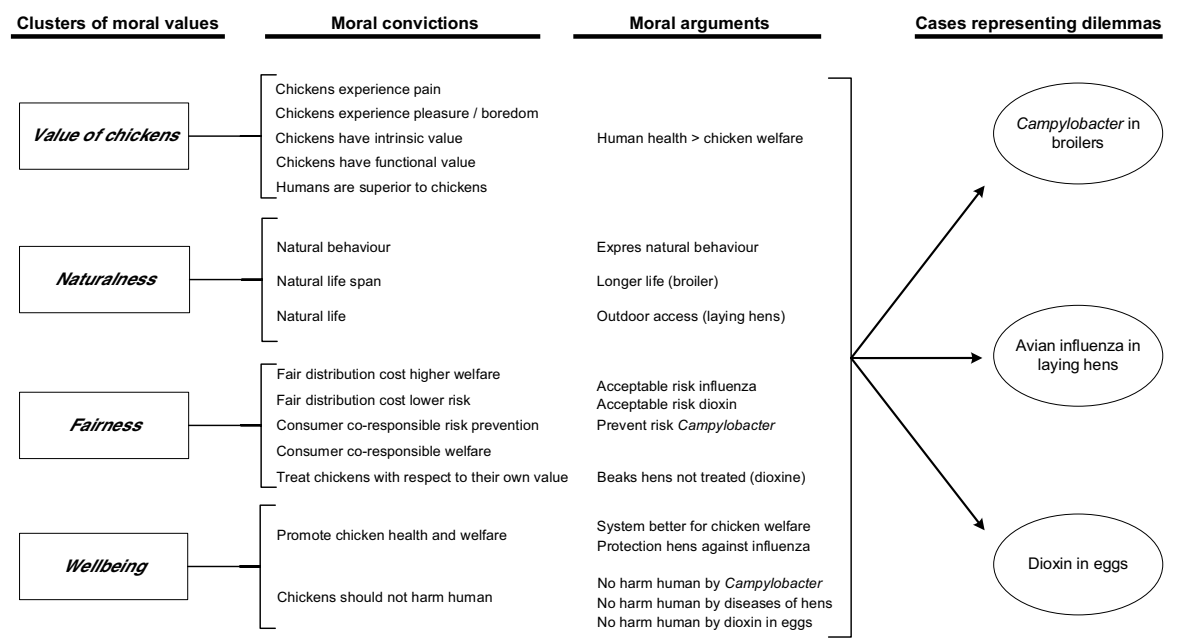

Fig. 1 Framework for the analyses of moral convictions and moral arguments relevant for the judgment of three cases representing a dilemma of improving chicken welfare or reducing public health risks 
were considered. The main interest groups involved in the dilemma are chickensdepending on the case, these were laying hens or broilers-farmers, consumers of chicken products, and citizens who are at risk.

To explain the framework used, we will now give a concise overview of relevant literature and the public debate regarding the dilemma of improving chicken welfare or reducing public health risks. Literature review and analyses of the debate on the dilemma mentioned indicate that four clusters of moral values may be relevant to the study: Value of chickens, Naturalness, Fairness and Wellbeing (e.g. Beauchamp and Childress 2009; Bergstra et al. 2015; Cohen et al. 2009; Jensen et al. 2011; Mepham 2000; Michalopoulos et al. 2008). With regard to the dilemma presented, the interests of humans will be balanced against those of chickens. In the context of poultry husbandry, fundamental moral values related to humans and chickens will be expressed by people as personal moral convictions. Judging a dilemma will be influenced by moral convictions regarding the value of chickens. For example, chickens may have functional value, but can also have other values, such as relational value or intrinsic value (Cohen et al. 2009; Warren 1997). The functional value of chickens refers to their usefulness for humans, namely producing meat and eggs. A reason to attribute to chickens intrinsic value is acknowledging them as sentient beings who are able to experience pain, pleasure and boredom (Heeger and Brom 2001; Warren 1997). Balancing the interests and values related to humans against those related to chickens is influenced by the value of chickens and how their value is related to human value, i.e. the hierarchical position of a person with respect to animals (Cohen et al. 2009). For this study, the convictions 'chickens experience pain', 'chickens experience pleasure and boredom', 'chickens have intrinsic value', 'chickens have functional value' and 'hierarchical position' may be of relevance for the judgment and are included in the framework (Fig. 1).

In discussions about how animals should be kept, naturalness is often emphasized, especially by citizens (Bergstra et al. 2015; Boogaard et al. 2011a; Lassen et al. 2006; Vanhonacker et al. 2008; Verbeke 2009; Verhoog et al. 2007). Both citizens and farmers perceive freedom of movement and possibility to perform natural behaviour as important (Bergstra et al. 2015; Boogaard et al. 2011a; Te Velde et al. 2002), but citizens also see a natural life and a natural lifespan as being important in animal husbandry (Bergstra et al. 2015; Lassen et al. 2006). In the dilemma of improving chicken welfare or reducing public health risks, naturalness may play a role in the choice of husbandry system, because outdoor systems are in line with convictions regarding naturalness, such as freedom to express natural behaviour and leading natural lives. Therefore, 'natural behaviour' and 'natural life' are included in our framework. For broilers specifically, 'natural lifespan' is of relevance, because broilers used in non-conventional systems are of a slower growing genetic line and are thus slaughtered at an older age and will be studied.

The third cluster of values we found relevant is fairness, which is also referred to as justice. When applied to the dilemma of improving chicken welfare or reducing public health risks, fairness may represent a fair distribution of costs for improving animal welfare and for reducing public health risks, and a fair distribution of responsibility for chicken welfare and risk prevention among farmers and consumers. The corresponding convictions for this study are 'fair distribution of costs of higher 
welfare', 'fair distribution of costs of lower public health risks', 'consumers are coresponsible for risk prevention', and 'consumers are co-responsible for chicken welfare'. With regard to animals, fairness has been defined as respect for the intrinsic values of animals (Mepham 2000). It means that chickens have a value of their own, independently from their instrumental value to humans, and should be treated with respect to their own value. In the present study, fairness will refer to respect for the intrinsic value of chickens: 'treat chickens with respect to their own value'.

The last cluster of moral values concerns wellbeing. Wellbeing means promote health and welfare, do not harm, and protect against harm (Beauchamp and Childress 2009; Cohen et al. 2009; Mepham 2000). The dilemma outlined above relates to a change of husbandry system, which may be beneficial for poultry welfare, but may also entail higher risks to public health or food safety hazards. The general public and poultry farmers view poultry health, public health and food safety as important issues for poultry husbandry (Van Asselt et al. 2015). Thus, as regards the dilemma, the convictions 'promote chicken health and welfare' and 'should not harm human health' are relevant to the framework and are included. Related to the moral convictions as described above and, in the framework (Fig. 1), we formulated statements (see Table 3), which were included in the questionnaire.

In this study, three cases were presented to survey participants regarding the dilemma of improving chicken welfare or reducing public health risks. In each case, certain specific moral arguments are relevant. These moral arguments are related to the previously described moral convictions (Fig. 1). Because we were interested to study the judgments in three specific cases, only relevant moral arguments for the specific cases are included. Consequently, not for every moral conviction a moral argument is included in the framework in Fig. 1. Some of the moral arguments are relevant for all cases, for example 'human health is more important than chicken welfare', 'express natural behaviour', and 'the system is better for chicken welfare'. Other arguments are specific to one case, such as 'longer life for broilers' for the Campylobacter case; 'outdoor access' for the avian influenza and dioxin case; and 'beaks are not treated' for the dioxin case. For each case six arguments were chosen. Based on these arguments for each case, six statements were formulated and included in the questionnaire (see Table 2).

\section{Cases Representing the Dilemma}

For methodological reasons, the three cases representing the dilemma were formulated in two ways. The two cases representing a dilemma regarding Campylobacter in broilers and dioxin in eggs describe a situation in which a broiler farmer and a laying hen farmer switch to a husbandry system that is considered more welfarefriendly than the old system but may imply higher food safety risks. The avian influenza case describes a switch from an outdoor system to a less welfare-friendly indoor system with fewer risks of avian influenza than the outdoor system. In the questionnaire, the three cases were presented to the participants. After each case the participants were asked to give their opinions (agree, neither agree nor disagree, or disagree) on the choice of a poultry farmer for a husbandry system. 


\section{Campylobacter Case}

A poultry farmer keeps his broiler chickens in a conventional indoor husbandry system: in a barn with litter on the floor, and the broilers are slaughtered at the age of 42 days. The farmer would like to change from the conventional system to a conventional plus (indoor) system. Compared to a conventional system, the broilers in a conventional plus system are offered more space, enrichment (straw) and will be slaughtered at the age of 56 days. Ten per cent of conventional broiler meat is infected with the intestinal bacterium Campylobacter. In the new system, the Campylobacter contamination of broiler meat will increase to $30 \%$, due to the longer growing period of the broilers. In humans, contamination with Campylobacter may cause intestinal infections. Contamination can be prevented through hygienic food handling and thorough cooking of broiler meat.

\section{Avian Influenza Case}

A poultry farmer keeps his laying hens in a free-range system with outdoor access. The hens have access to an outdoor run for eight hours a day. Hens kept in this system with outdoor access have an introduction rate of avian influenza that is 11 times higher than for hens kept in systems without outdoor access. Therefore, the poultry farmer decides to keep his hens permanently indoors. The avian influenza virus is transmitted to several bird species and is usually not contagious to humans. Influenza viruses change continuously. In future, avian influenza may infect humans and may cause human diseases varying from eye infections to flu.

\section{Dioxin Case}

A laying hen farmer switches from an indoor non-cage husbandry system to an organic system. Compared to the indoor non-cage system, hens in this organic system have more space, access to an outdoor run for eight hours a day, have untreated beaks, and receive organic feed. When the farmer kept his hens in the indoor system, the dioxin levels in the eggs were well below the legal norm. In the system with outdoor access, hens can take up dioxin from the environment and the average dioxin level in eggs has increased, but is still within the legal norm. Dioxin is a chemical compound, which after a prolonged uptake may cause cancer in humans. The norm is set at a level such that the cancer risk is minimal.

\section{Survey}

A quantitative survey was done by means of an online questionnaire in March and April 2014. We formulated the survey questions based on the moral convictions, moral arguments and cases presented in the framework (Fig. 1). Prior to data collection, the questionnaire was pilot tested for clarity and comprehensibility of the questions by representatives of the two stakeholder groups. Based on these comments, 
the questionnaire was then further revised and subsequently executed. The questions addressed (1) moral convictions concerning chickens and humans; (2) the judgments of three cases; (3) arguments of relevance for the judgment of the dilemmas; and (4) socio-demographic characteristics of the participants. For the questions regarding the moral convictions (Fig. 1), we asked the participants to score to what extent they agreed with 15 statements (Table 3) on a five-point Likert scale ranging from strongly disagree (1) to strongly agree (5). The participants were then presented first with the Campylobacter case and were asked to give their opinions (agree, neither agree nor disagree, or disagree) on the choice made by a poultry farmer in a case that represents a dilemma of improving broiler welfare or increasing the risk of Campylobacter. Participants were then asked to rate the importance of six statements regarding the moral arguments for their judgment of the Campylobacter case on a scale of 1 to 5 ( $1=$ very unimportant, $5=$ very important $)$. Subsequently, the other two cases, the avian influenza and dioxin case, were presented. Participants were again asked to make a judgment and to rate the importance of six statements regarding moral arguments (Table 2).

\section{Participants}

The general public and poultry farmers were considered relevant stakeholder groups for studying the dilemma of improving chicken welfare or reducing public health risks. The opinions of the general public concerning livestock husbandry, most notably channelled through NGOs, have become important (Boogaard et al. 2011b). The general public were studied in their role as citizens, because citizens, without being necessarily consumers, may be involved in public debates about poultry husbandry (Harvey and Hubbard 2013). The views of poultry farmers were regarded as relevant because they are most directly involved in choosing and investing in poultry husbandry systems.

Representatives of Dutch citizens and poultry farmers filled in the questionnaire. CentERdata (www.centerdata.nl), a research institute specialized in online survey research, invited citizens from their CentERpanel to participate in the survey. The CentERpanel is considered to be a representative sample of the Dutch population. CentERdata approached 3344 CentERpanel citizens, of whom 2373 (71.0\%) started to fill in the questionnaire, and $2259(67.6 \%)$ completed the questionnaire. Dutch poultry farmers were invited to participate in the questionnaire by a digital newsletter of the Dutch organization of poultry farmers (NOP). We also posted several articles on websites dealing with poultry husbandry, and a website concerned with agriculture in general. The newsletter and websites were freely available. One hundred poultry farmers fully completed the questionnaire. The data of CBS Statistics Netherlands (2018, April 04) indicate that 2046 farms kept poultry professionally in 2014. Information about the main socio-demographic features of the respondents, citizens and poultry farmers, are presented in Table 1. 
Table 1 Socio-demographic characteristics of the respondents

\begin{tabular}{|c|c|c|c|}
\hline & $\begin{array}{l}\text { Citizens } \\
(\mathrm{n}=2259)\end{array}$ & $\begin{array}{l}\text { Poultry } \\
\text { farmers } \\
(n=100)\end{array}$ & CBS Statline $^{\mathrm{a}}$ \\
\hline \multicolumn{4}{|l|}{ Gender (\%) } \\
\hline Male & 52.2 & 88.0 & 49.2 \\
\hline Female & 47.8 & 12.0 & 50.8 \\
\hline \multicolumn{4}{|l|}{ Age $(\%)$} \\
\hline $15-34$ years & 16.6 & 11.0 & 29.3 \\
\hline $35-54$ years & 36.8 & 73.0 & 34.2 \\
\hline$>55$ years & 46.6 & 16.0 & 36.5 \\
\hline \multicolumn{4}{|l|}{ Education (\%) } \\
\hline Low & 26.7 & 28.0 & 30.9 \\
\hline Intermediate & 29.3 & 43.0 & 41.0 \\
\hline High (Bachelor/Master) & 44.0 & 29.0 & 28.1 \\
\hline
\end{tabular}

${ }^{\mathrm{a}}$ Data from Statline (CBS Statistics Netherlands) dated 01-03-2014, which represent the average of the Netherlands

\section{Statistical Analyses}

Only fully completed questionnaires were included in the analyses. Data were processed and analysed using SPSS 22.0. Two cases, the Campylobacter and dioxin cases, described a switch to a system that benefits chicken welfare at the expense of public health. For the avian influenza case, however, the case was formulated the other way round for methodological reasons, thus describing a switch from a system that benefits animal welfare to a system that benefits public health. To facilitate the analyses of the dilemmas, for the influenza case the categories disagree and agree were switched so that for all three cases an 'agree' signifies agreement with a farmer's choice of a husbandry system that may benefit chicken welfare, and a 'disagree' signifies disagreement with a farmer's choice of a husbandry system that may benefit chicken welfare. The Chi square test was done to analyse the association between the judgment of the cases and the stakeholder group. Analysis of variances was used to explore the association between (1) the mean importance scores for the moral arguments and the judgment of the case; (2) the mean level of agreement with statements regarding moral convictions and stakeholder group; and (3) the mean level of agreement with statements regarding moral convictions and judgment of the case. One-way analysis of variance (ANOVA) was done if variances were homogeneous according to Leven's test. If variances were not homogeneous, the Welch test was used. If the effect of the judgment of a case on the arguments was significant, the post hoc Games-Howell test for multiple comparisons was done to analyse differences between the groups that agreed, neither agreed nor disagreed, or disagreed with a farmer's choice of a system that may benefit chicken welfare. 


\section{Results}

To gain insight into the judgment of the dilemma and relevant moral arguments and convictions, we first present the judgments of citizens and poultry farmers on the three cases. Second, the importance of the moral arguments for the judgment of the three cases will be shown. Next, the moral convictions of the citizens and poultry farmers will be presented, and finally, these moral convictions will be presented in relation to the judgments of citizens and farmers regarding the three cases.

\section{Opinions on the Cases}

Citizens and poultry farmers had different opinions on the three cases representing a dilemma of improving chicken welfare or reducing public health risks from (1) Campylobacter in broilers; (2) avian influenza in laying hens; and (3) dioxin in eggs (Fig. 2). Citizens were more likely than farmers to agree with a system that benefits chicken welfare at the expense of public health, while farmers were more likely than citizens to disagree with a system that benefits chicken welfare for the Campylobacter case $\left(\chi^{2}(2)=11.23, p=0.004\right)$, the avian influenza case $\left(\chi^{2}(2)=75.97\right.$, $p<0.001)$, and the dioxin case $\left(\chi^{2}(2)=179.65, p<0.001\right)$. Of the three cases, citizens most often agreed with a system that benefits chicken welfare when considering the dioxin case $(50 \%)$, while farmers most often agreed with a system that benefits chicken welfare when considering the Campylobacter case $(30 \%)$.

For the Campylobacter case, the difference between citizens and farmers was smaller than for the influenza and dioxin cases. Of the three cases, citizens and farmers disagreed most often on the avian influenza case. Notable is the high

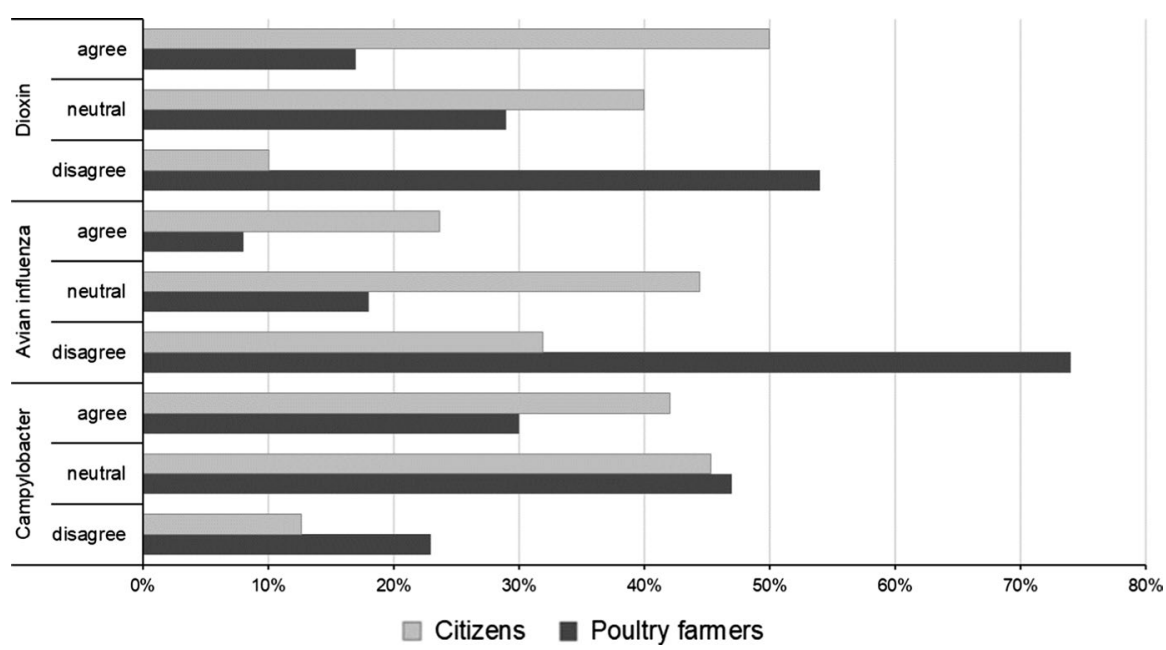

Fig. 2 Percentage of citizen and poultry farmer respondents who agreed, were neutral (neither agreed, nor disagreed), and disagreed with the choice of a husbandry system that benefits chicken welfare at the expense of public health for Campylobacter in broilers, avian influenza in laying hens, and dioxin in eggs 


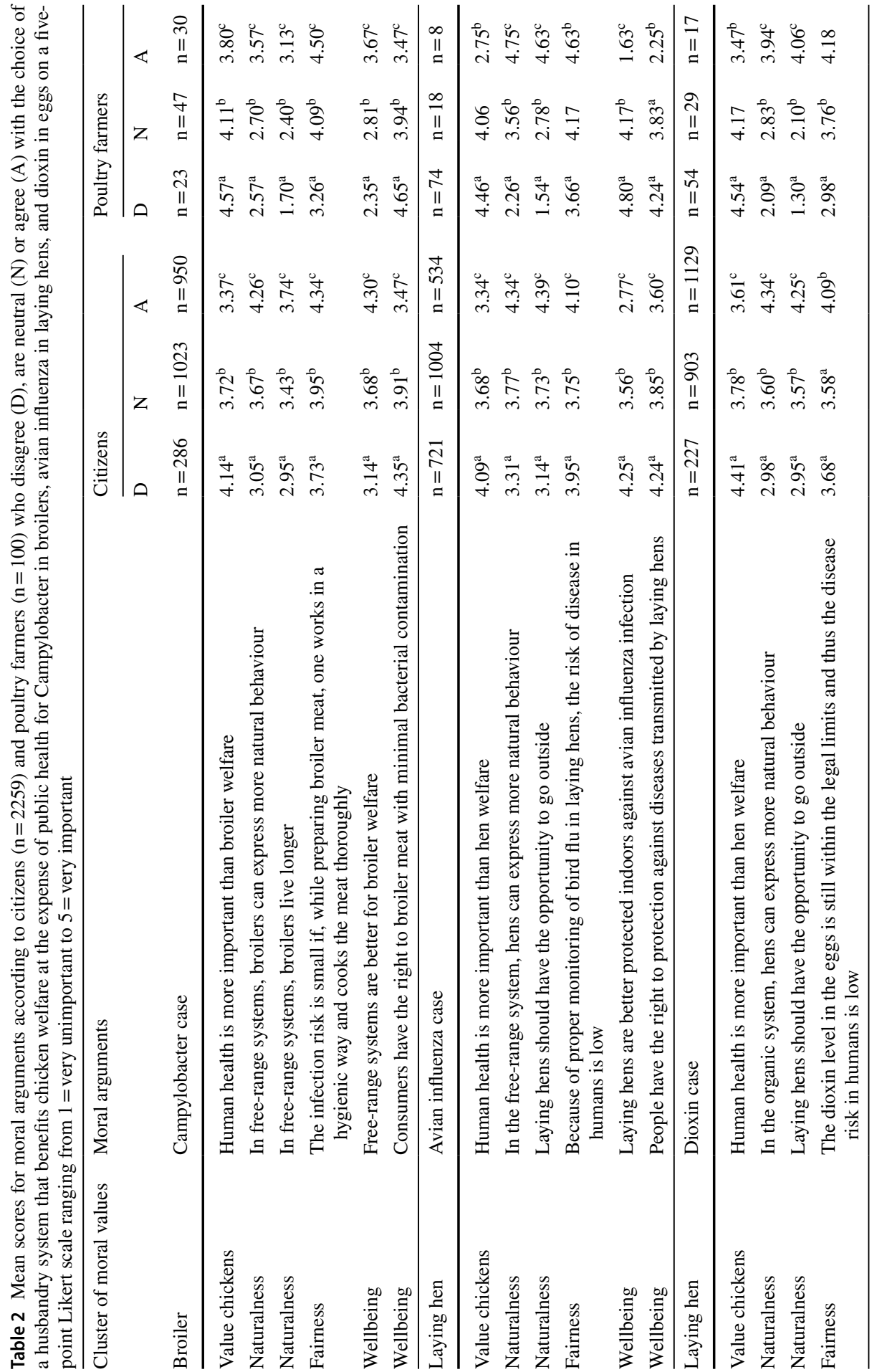




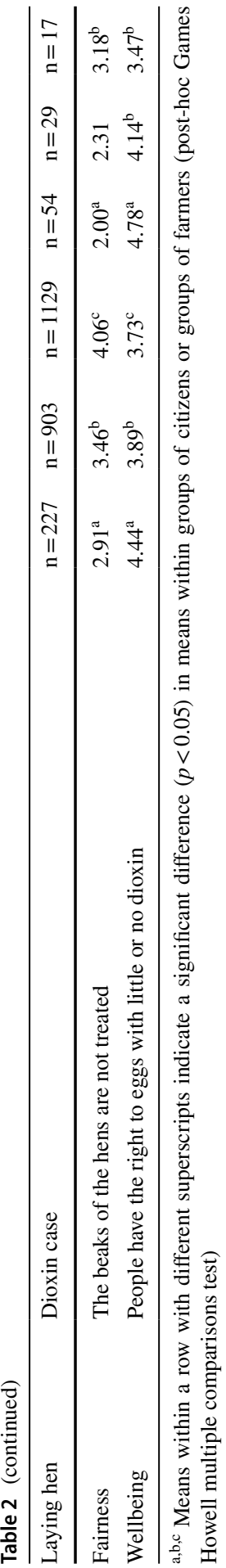




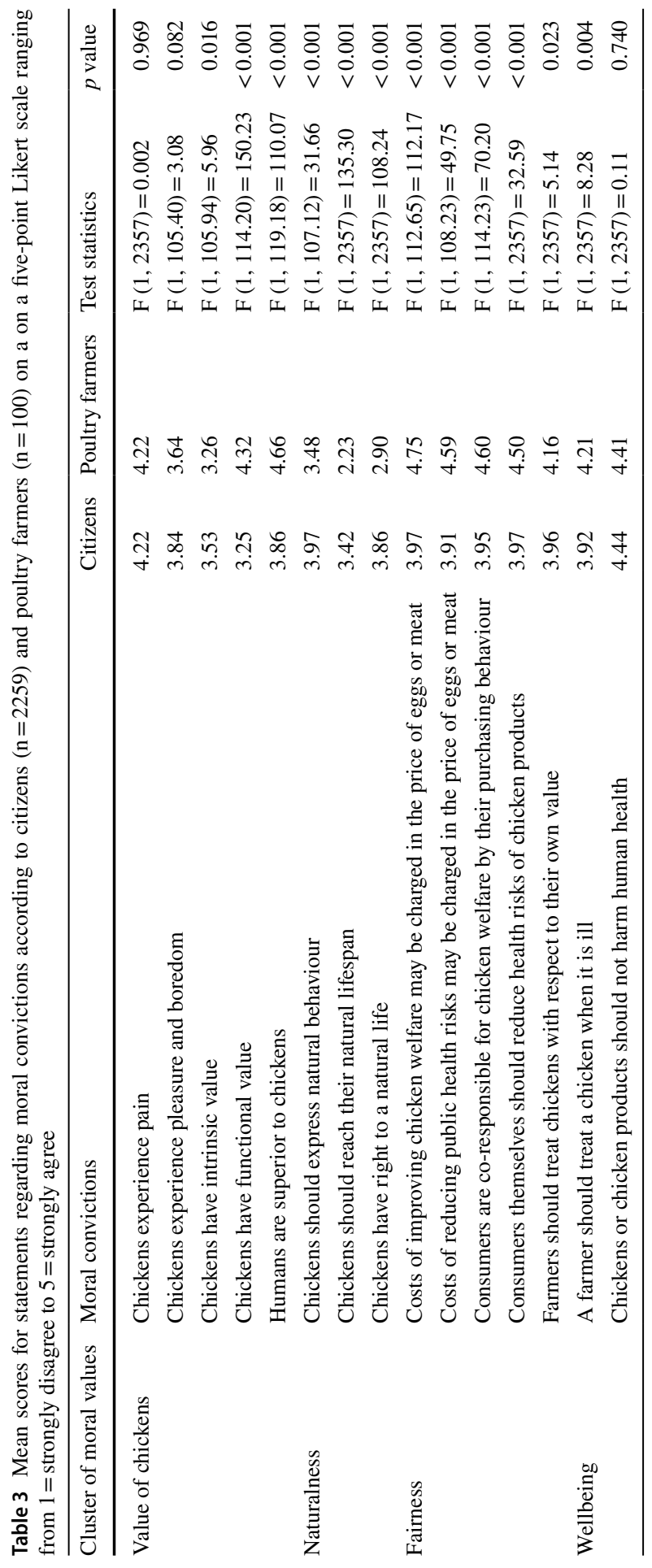


percentage of farmers (74\%) who disagreed with a system that benefits hen welfare and increases the risk of avian influenza introduction. Of the citizens, about $40-45 \%$ neither agreed nor disagreed with the three cases, while among poultry farmers, a comparable neutral score was only found for the Campylobacter case.

\section{Moral Arguments}

After making a judgment of the cases, the respondents scored the importance of moral arguments for their judgment of the three cases (Table 2). For all three cases, citizens and farmers who agreed with a choice of a system that favours chicken welfare scored 1) all arguments concerning naturalness; 2) all arguments concerning fairness; and 3) the argument concerning wellbeing 'free range systems are better for broiler welfare', as more important $(p<0.05)$ than those who favoured a system with fewer public health risks. Respondents who disagreed with the choice of a system with better chicken welfare and higher public health risks scored the arguments regarding value of chickens - 'human health is more important than chicken welfare', and the argument regarding wellbeing, namely 'not harm human', as more important $(p<0.05)$ than respondents who agreed with the choice of a system favouring chicken welfare. In citizens, a difference of more than 1.0 was found between the agree group and the disagree group for arguments regarding naturalness - 'chickens can express more natural behaviour', and 'hens should have the opportunity to go outside', for the argument regarding wellbeing chicken in the Campylobacter case, and for the argument 'beaks of the hens are not treated' in the dioxin case. The scores of the farmers who agreed and disagreed differed for almost all arguments by more than 1.0. A difference of more than 1.8 was found between the agree and disagree groups for arguments regarding naturalness-'chickens can express more natural behaviour', and 'hens should have the opportunity to go outside' - in the influenza and dioxin case, and regarding wellbeing in the influenza case. Notable are the low scores of farmers who disagreed with the choice of a system that benefits chicken welfare for all the arguments regarding naturalness.

\section{Moral Convictions}

Table 3 shows the mean scores of citizens and poultry farmers for moral convictions relevant in the context of the dilemma of improving chicken welfare or reducing public health risks. Citizens scored the statement 'chickens or chicken products should not harm human health', which reflects the wellbeing of humans, as highest, and the statement 'chickens have functional value' lowest of all statements. Poultry farmers scored the statement 'costs of improving chicken welfare may be charged in price of eggs or meat', which reflects fairness of distribution of costs, highest and they scored 'chickens should reach their natural lifespan' lowest of all statements. The mean scores of citizens and farmers did not differ $(p>0.05)$ for the two statements regarding chicken sentience, namely 'chickens experience pain', and 'chickens experience pleasure and boredom', and did not differ for the statement 'chickens or chicken products should not harm human health' (wellbeing). All other 
statements were scored differently $(p<0.05)$ between citizens and poultry farmers. Citizens scored the statements regarding the intrinsic value of chickens, and the three statements regarding naturalness higher $(p<0.05)$ than farmers did. The statements 'chickens have functional value', 'humans are superior to chickens', the five statements regarding fairness, and 'a farmer should treat a chicken when it is ill' were scored higher by farmers than by citizens $(p<0.05)$. The biggest differences between scores given by citizens and poultry farmers related to statements concerning the value of chickens, namely 'chickens have functional value', and 'humans are superior to chickens', and statements concerning naturalness.

\section{Moral Convictions Relating to Opinions on the Cases: A Comparison Between Citizens and Farmers}

Moral convictions relating to the opinions on the cases regarding Campylobacter in broilers, avian influenza in laying hens, and dioxin in eggs are presented in the "Appendix" in Tables 4, 5 and 6. For all three cases, the scores of the agree and disagree groups in citizens and poultry farmers show the same pattern. All respondents, both citizens and poultry farmers, who agreed with the choice of a husbandry system that benefits chicken welfare, gave higher scores for statements regarding chicken sentience, 'chickens have intrinsic value', naturalness, fairness and 'a farmer should treat a chicken when it is ill', and lower scores for the statements 'chickens have functional value' and 'humans are superior to chickens' than respondents who disagreed.

\section{Discussion}

Society is increasingly concerned about poultry husbandry in general and chicken welfare in particular. To address these concerns, poultry husbandry systems have been adapted and the number of farms offering outdoor access to chickens has been growing. With these developments, new concerns have come to the fore about potential public health and food safety risks associated with keeping chickens in alternative and outdoor husbandry systems. As a result, a dilemma of choosing a system that improves chicken welfare or reduces public health and food safety risks has arisen. The question is how to address such dilemmas. Insight into stakeholders' judgments of these dilemmas and their arguments and underlying moral convictions, may provide input for developing or adapting husbandry systems in such way that they can count on support from society. Therefore, the objective of this study was to (1) to gain insight into views of citizens as compared to poultry farmers on three cases representing a dilemma of improving chicken welfare or reducing public health risks; (2) the valuation of moral arguments relevant for the dilemma; and (3) the underlying moral convictions. To this end, a quantitative survey by means of an online questionnaire was conducted among Dutch citizens and poultry farmers. The citizens' sample was considered representative for Dutch citizens. It should be noted that due to the methods of invitation, the selection of poultry farmers might have been biased, for example towards more knowledgeable farmers. 


\section{Judgments of the Cases and Moral Arguments}

Citizens and poultry farmers judged three cases dealing with the choice of farmer for a husbandry system that benefits chickens or a system that reduces public health of food safety risks for Campylobacter, avian influenza, or dioxin in eggs. For all three cases, citizens agreed with the choice of a husbandry system that benefits chicken welfare at the expense of public health more often than did farmers. These results are in line with other studies that describe that, in general, citizens have negative feelings towards intensive indoor husbandry systems (Eurobarometer 2005, 2007; Musto et al. 2014; Van Asselt et al. 2015, 2018) and prefer husbandry systems with outdoor access (Van Asselt et al. 2015; Vanhonacker et al. 2016).In contrast farmers often have negative attitudes towards outdoor systems (Gocsik et al. 2016; Stadig et al. 2016; Van Asselt et al. 2015). Of the three cases, farmers most often agreed with the Campylobacter case (30\%), which represented a switch from a conventional indoor to a conventional plus system. Compared to the conventional system, the conventional plus system offers broilers more space and enrichment, and broilers are slaughtered at an older age. Nevertheless, the conventional plus system is also an indoor system. The relatively strong agreement of farmers with the Campylobacter case may also be explained by the farmers' preference for indoor systems (Gocsik et al. 2016; Stadig et al. 2016; Van Asselt et al. 2015).

For the Campylobacter and dioxin case, more citizens agreed than disagreed with a system that benefits chicken welfare at the expense of public health, while for the avian influenza case more citizens disagreed than agreed with a system that benefits chicken welfare at the expense of public health. The reason that citizens choose not to favour the outdoor system for the avian influenza case might be that in contrast to the other two cases avian influenza affects also hen health negatively and in case of an avian influenza outbreak chickens have to be culled. Citizens showed a higher agreement on the dioxin case than on the influenza and Campylobacter case. The welfare improvement from an indoor non-cage to an organic system in the dioxin case is larger than in the other two cases. For a considerable group of citizens, this welfare improvement might be sufficient to outweigh the health risks for human, or they perceive the human health risks as small because eggs are controlled on dioxin levels.

A considerable group of respondents, especially citizens, neither disagreed nor agreed with a system that benefits chicken welfare. The scores of these "neutral" respondents for the moral arguments were in between the scores of the disagree and agree groups. This neutral judgment might suggest that these respondents required more information to judge the case, or had less strong opinions than the disagree and agree groups, or viewed several arguments equally important and could not make a trade-off.

It is interesting to note that citizens and poultry farmers who made the same judgments of the cases use the same moral arguments. Those who agreed with a system that benefits chicken welfare scored the moral arguments regarding naturalness, fairness, and wellbeing of chickens higher, and the arguments 'humans are superior to chickens', 'not harm human', and 'not harm chicken' lower than the respondents who disagreed. The arguments regarding naturalness- 'express natural behaviour' and 'opportunity to go outside' - were scored considerably different by the agree and disagree respondents of the two stakeholder groups. This difference suggests that the judgment of the dilemma of improving chicken welfare or reducing public 
health risks is predominantly influenced by how important one views naturalness in relation to chickens and chicken welfare.

\section{Moral Convictions}

In this study, citizens and poultry farmers agreed with most moral convictions presented. Citizens and farmers agreed on the strength of the convictions regarding not harm human and sentience of chicken, which was also found by Bergstra et al. (2015) in the context of pig husbandry. This agreement on sentience-chickens experience pain, and pleasure and boredom-may still lead to diverging views regarding a dilemma in a practical case, because other convictions, such as the conviction regarding naturalness, are balanced against it. In a practical case, attribute sentience to chickens may imply for a citizen respect for a natural life and for a farmer providing good care to his chickens.

Although citizens and poultry farmers agreed on most moral convictions, they valued most moral convictions differently. Citizens recognized more often than farmers the importance of the intrinsic value of animals (Bergstra et al. 2015). Farmers valued the convictions regarding 'humans are superior to chickens', and 'chickens have functional value' higher than citizens. This suggests that for them, the value of chickens is mainly based on their usefulness to people. Also, for the convictions regarding naturalness, a big difference was found between citizens and farmers. Citizens perceived convictions regarding naturalness, such as 'express natural behaviour' and 'natural life', as more important than did farmers. This is in line with studies on stakeholders' perceptions of animal welfare, which show that citizens view animal welfare predominantly in terms of leading natural lives and professionals as biological functioning and affective states of the animal (Bergstra et al. 2015; Fraser et al. 1997; Te Velde et al. 2002; Vanhonacker et al. 2008).

The scores for the moral convictions regarding a fair distribution of responsibility and costs showed some interesting results. Although citizens and poultry farmers agreed that the costs of improving chicken welfare and reducing public health risks may be charged in the price of eggs or meat, poultry farmers agreed with these statements more strongly than citizens did. Farmers will argue that they are responsible for producing eggs and chicken meat in accordance with minimal requirements for chicken welfare and risks for public health and food safety as laid down in legislation. When society calls for chicken welfare or public health and food safety above this statutory level, farmers might argue that they are not responsible to pay for these improvements. On the other hand, citizens might argue that the requirements as set in legislation are minimal requirements and farmers are responsible for health and welfare of their chickens, and therefore farmers should pay for the improvements.

In the questionnaire, the moral convictions regarding humans and chickens were asked independently from the cases. Because the moral arguments were associated with the judgments of the cases, and the moral arguments used in the cases were based on the moral convictions, it was expected that moral convictions would also be associated with the judgments of the cases. Indeed, in both citizens and poultry farmers the moral convictions were associated with the judgments, and especially the 
convictions regarding naturalness, and the value of chickens seemed relevant for the judgments. The people who disagreed with a judgment in favour of chicken welfarea higher percentage of farmers than citizens-scored the moral convictions 'humans are superior to chickens', and 'chickens have functional value' higher, and the convictions regarding sentience chickens and intrinsic value of chicken lower than those who agreed. These results confirm that the value of chickens-being sentient and having intrinsic value or having functional value (Cohen et al. 2012) - and naturalness (Bergstra et al. 2015), in terms of expressing natural behaviour, are relevant convictions for the way in which the interests of chickens are weighed against the interests of humans.

The convictions regarding sentience, the value of chickens and naturalness, are all related to ethical views on animal welfare. Sentience, the capacity to feel pain and emotions, is, according to several ethical theories, a reason to respect the species specific needs and interests of animals (e.g. Appleby and Sandoe 2002; Bentham 1789; Singer 1995). Citizens who keep animals for companion or recreational purposes, may have more empathic feelings towards animals than farmers who keep animals for productions purposes (Heleski et al. 2006; Musto et al. 2014). These empathic feelings of citizens for animals may imply that citizens emphasise the sentient capacity of the animals (Evans and Miele 2008). The convictions related to sentience, however, were not valued differently by citizens and poultry farmers. Citizens, when confronted with poultry husbandry, may view sentience predominantly from an empathic perspective, while poultry farmers view sentience from a biological or functional perspective.

Sentience may be a reason to attribute to these animals intrinsic value (Heeger and Brom 2001). Respect for the interests of animals may imply respect for the animal living its life according to its nature or telos (Rollin 1981). This view was confirmed in citizens and farmers who believed that chickens have a right to a natural life. The respect for telos is contained in the concept of animal welfare that considers that good welfare means leading a natural life (Fraser 2003; Fraser et al. 1997). Although 'chicken or chicken products should not harm humans' was an important moral conviction for both citizens and farmers, a proportion of the citizens and farmers judged the dilemma in favour of chicken welfare. For them, convictions regarding the interests of chickens may be strong enough to outweigh those regarding human health, and to cause them to judge the dilemma in favour of chicken welfare. People who view humans to be superior to chickens - in this study more poultry farmers than citizensmay value chickens predominantly for their functional value. They may perceive animal welfare in terms of biological functioning - health, growth and production rateand view naturalness less important for chickens and their welfare. They will balance the values related to the interests of chickens against other values, such as 'not harm human'. As a result, these people may judge the cases in favour of human health.

\section{Context}

The remaining question is: Why do different interest groups, such as citizens and farmers, value some moral convictions differently? The differences between poultry farmers and citizens might be explained by their context: whether or not someone is involved in poultry husbandry, which has been explained by the 'three-layered concept 
of moral convictions' by Cohen (2010). Fundamental moral values, such as respect for autonomy, justice and wellbeing, are part of public morality (Beauchamp and Childress 2009; Mepham 2000). Being a farmer or being a member of the general public, however, influences the valuation of moral convictions, which are based on those fundamental moral values regarding either humans or animals. Moreover, the practical context of people, and thus also their interests, will influence the balancing of moral convictions. It has been shown that farmers' decisions regarding husbandry systems are influenced by their farm characteristics and the possibility of converting to anothere.g. outdoor-system, risks of disease spread, and the economic consequences of a disease outbreak (Gocsik et al. 2015; Stadig et al. 2016). To elaborate on this, the public health risks of an avian influenza outbreak are small, because only a minority of avian influenza outbreaks are potentially a disease risk for humans. If avian influenza is diagnosed on a farm, chickens will be culled immediately, which implies that the human health risks is small. An influenza outbreak, however, has a high impact on the affected farm, because chickens will be culled, and an outbreak also affects other farms because animal transportation is halted and export restrictions imposed (Backer et al. 2011). This high impact of avian influenza outbreaks on farmers' wellbeing and the viability of the farm will influence farmers' moral convictions and arguments regarding naturalness and outdoor systems. Farmers might therefore have valued the intrinsic value of chickens lower and the functional value of chickens higher than did citizens. Another example is a farmer's practical or economically inability to convert to an outdoor system may influence his opinion on the importance of naturalness for chickens.

Citizens, however, value chickens for their intrinsic value and do not take economic consequences or farm characteristics into consideration when they value moral convictions regarding chickens. Nowadays, only a small number of people are involved in livestock farming and farms are often "closed" systems, so that citizens are not always aware of the limitations that farmers have to deal with. Other examples of the context dependency of citizens' views are food or livestock-related incidents. In the period March to April 2014, when this research was done, no animal disease outbreaks or food incidents occurred in the Netherlands. Citizens may have perceived the public health risks as presented in the cases in this study as general risks and not as personal risks. In situations of animal disease outbreaks, such as avian influenza, or food incidents, such as the dioxin affair, people may feel anxious and uncertain about the risks, and may make different judgments and use different arguments from those we found in this study (Bults et al. 2011). It is important to note that citizens cannot be regarded as one group. It has been shown that socio-demographic characteristics - in particular gender and experience with animals - are associated with perception and moral convictions related to animals and their welfare (e.g. Bergstra et al. 2017; Cohen et al. 2012; Kendall et al. 2006). Consequently, within citizens different judgments and moral convictions related to the dilemma may be found.

\section{Framework}

The framework used in this study to structure convictions and arguments relevant to the dilemma presented was based on existing multi-criteria frameworks and the debate on 
the dilemma. Although the framework might not be complete-for example, we did not include an argument for each moral conviction-the framework was useful to analyse moral convictions and arguments involved in a complex dilemma of improving animal welfare or public health risks. Based on the results, we can conclude that moral convictions related to the moral values value chicken and naturalness are important for judging the dilemma of improving chicken welfare or reducing public health risks and should be considered in ethical frameworks when studying dilemmas in animal husbandry.

\section{Conclusion and Implications}

Judgments by citizens and poultry farmers regarding the dilemma are related to their valuation of moral arguments and moral convictions, and are context-dependent. People, more citizens than farmers, who choose a husbandry system that benefits chicken welfare at the expense of public health value convictions related to the intrinsic value of chickens, sentience, and naturalness - expressing natural behaviour, natural lifespan and natural life-as more important than people who choose a system in favour of public health. Poultry farmers focus on the functional value of chickens and view a fair distribution of cost for welfare improvement and risks prevention important. Moreover, we argued that the judgments and moral convictions are context-dependent and this may explain the differences found between citizens and poultry farmers. To comply with societal concerns on poultry husbandry, moral convictions and arguments of both stakeholder groups should be considered. Starting a dialogue between citizens and farmers based on shared moral values considering humans and animals might help to shorten the distance between poultry farmers and society. Currently the majority of the poultry farms are closed systems. Opening the farms, such as initiatives to invite citizen on farms, and farms with visitors' rooms with view on the farm animals, might stimulate the dialogue between farmers and citizens. With that, successful innovations in poultry husbandry can be achieved.

Funding This work was supported by the Dutch Poultry Expertise Centre (PEC) and the Netherlands Organisation for Scientific Research (NWO).

\section{Compliance with Ethical Standards}

Conflict of interest The authors declare that they have no conflict of interest.

Open Access This article is distributed under the terms of the Creative Commons Attribution 4.0 International License (http://creativecommons.org/licenses/by/4.0/), which permits unrestricted use, distribution, and reproduction in any medium, provided you give appropriate credit to the original author(s) and the source, provide a link to the Creative Commons license, and indicate if changes were made.

\section{Appendix: Opinions on the Cases in Relation to Moral Convictions}

See Tables 4, 5 and 6. 


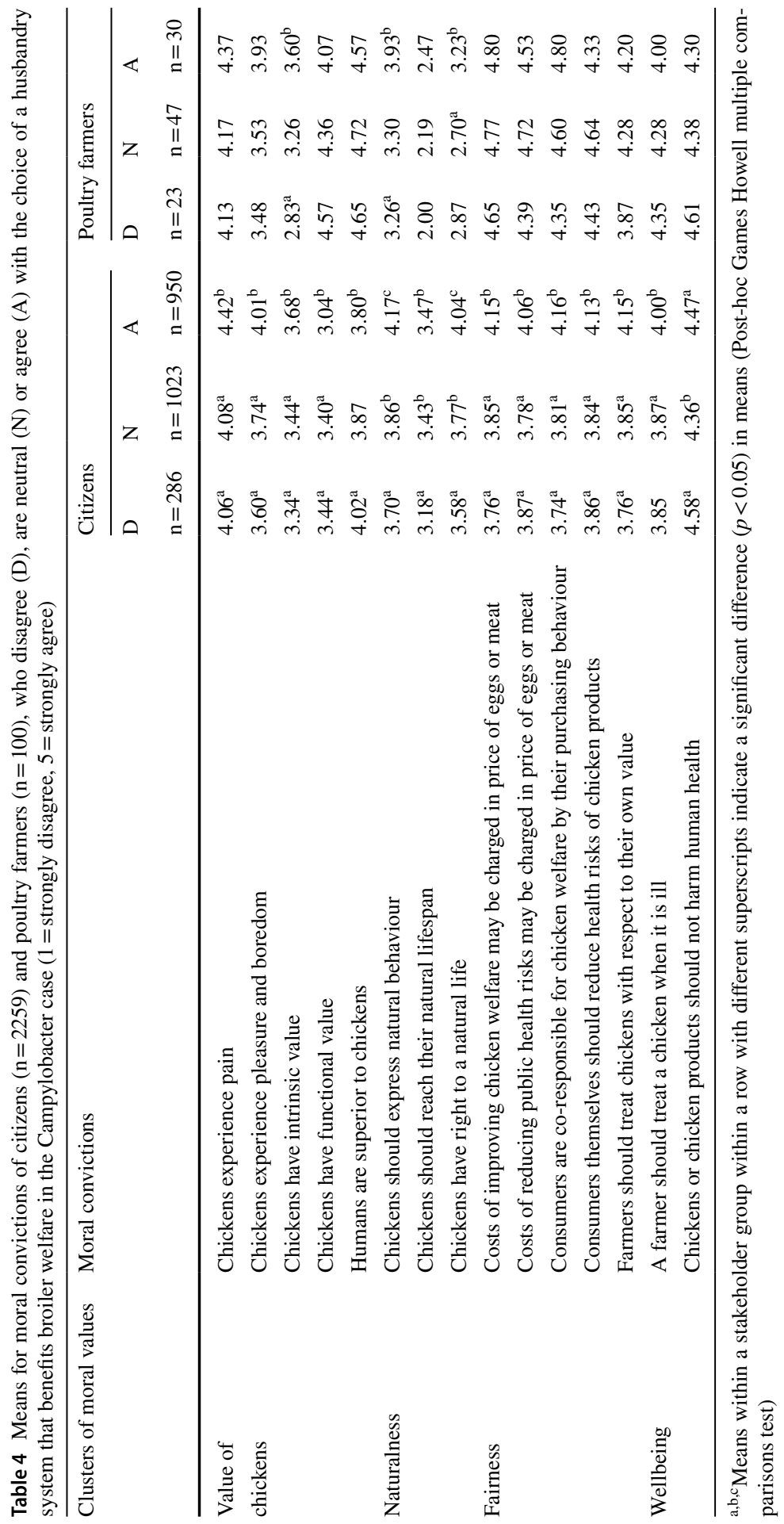




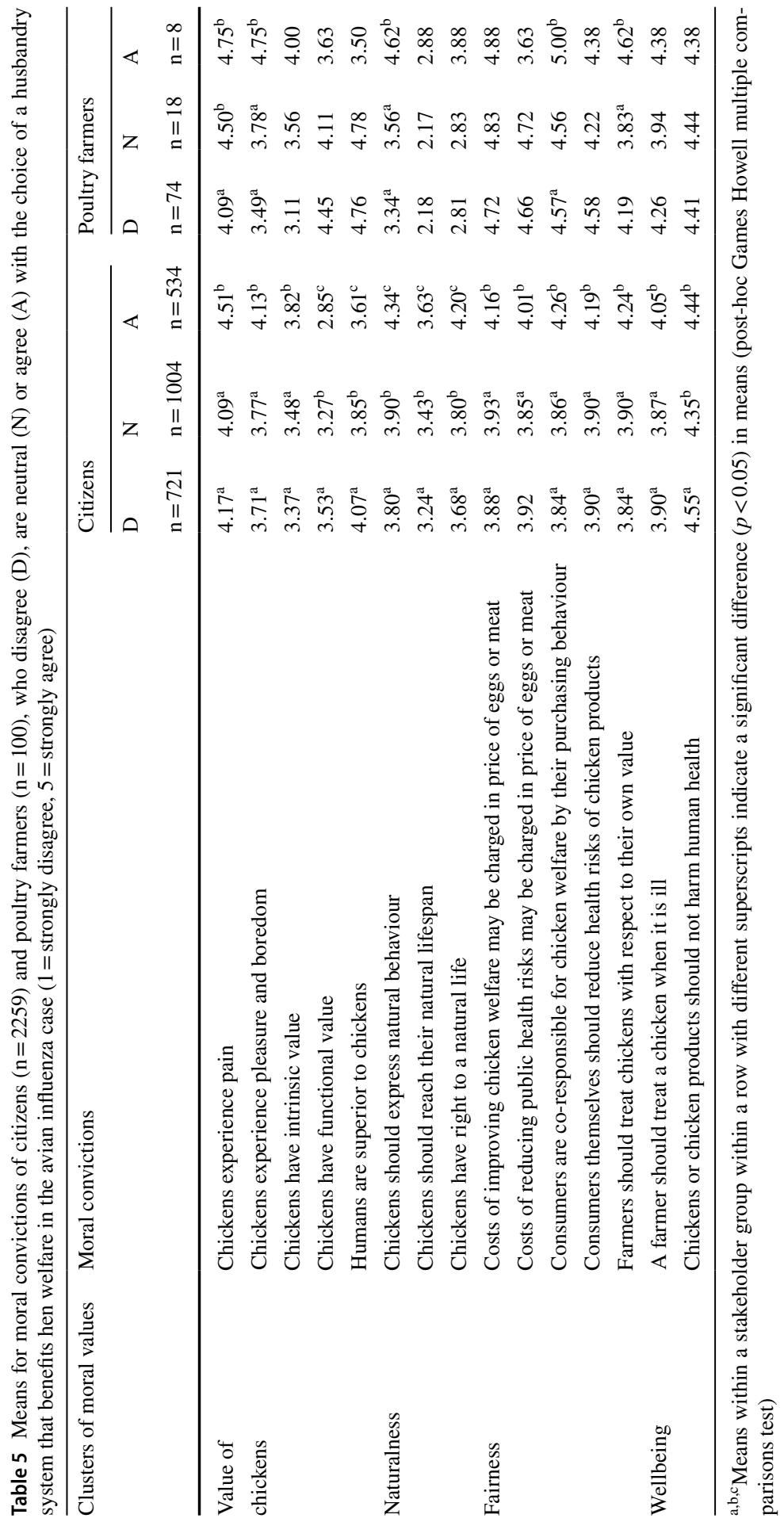




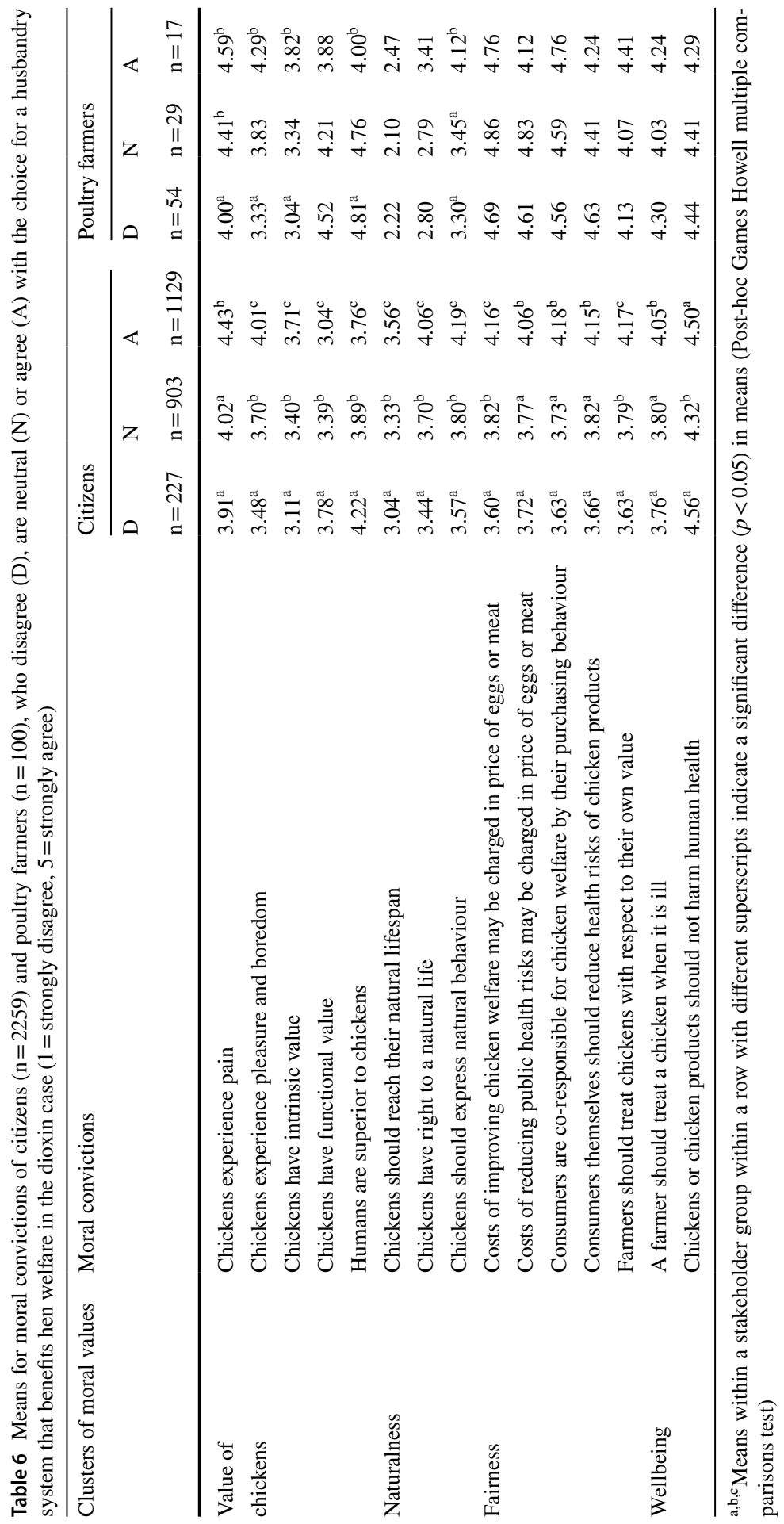




\section{References}

Appleby, M. C., \& Sandoe, P. T. (2002). Philosophical debate on the nature of well-being: Implications for animal welfare. Animal Welfare, 11, 283-294.

Backer, J., Fischer, E., Nodelijk, G. \& van Roermund, H. (2011). Vaccination against Avian Influenza: Epidemiological consequenses. In Backer, J., Bergevoet, R., Fischer, E., Nodelijk, G., Bosman, K., Saatkamp, H., \& van Roermund, H. (Eds.), Control of highly pathogenic avian influenza: Epidemiological and economic aspects, Rapport-Landbouw-Economisch Instituut, 80. Den Haag: Landbouw-Economisch Instituut (LEI).

Beauchamp, T. L., \& Childress, J. F. (2009). Principles of biomedical ethics. New York: Oxford University Press.

Bentham, J. (1789). Duty to minimize suffering. In A. Linzey \& P. A. B. Clarke (Eds.), Political theory and animal rights (pp. 135-137). London: Pluto.

Bergstra, T. J., Gremmen, B., \& Stassen, E. N. (2015). Moral values and attitudes toward Dutch sow husbandry. Journal of Agricultural and Environmental Ethics, 28, 375-401. https://doi.org/10.1007/ s10806-015-9539-x.

Bergstra, T. J., Hogeveen, H., \& Stassen, E. N. (2017). Attitudes of different stakeholders toward pig husbandry: A study to determine conflicting and matching attitudes toward animals, humans and the environment. Agriculture and Human Values, 34, 393-405. https://doi.org/10.1007/s1046 0-016-9721-4.

Boogaard, B. K., Boekhorst, L. J. S., Oosting, S. J., \& Sørensen, J. T. (2011a). Socio-cultural sustainability of pig production: Citizen perceptions in the Netherlands and Denmark. Livestock Science, 140, 189-200. https://doi.org/10.1016/j.livsci.2011.03.028.

Boogaard, B. K., Oosting, S. J., Bock, B. B., \& Wiskerke, J. S. C. (2011b). The sociocultural sustainability of livestock farming: An inquiry into social perceptions of dairy farming. Animal, 5, 1458-1466. https://doi.org/10.1017/S1751731111000371.

Bouwknegt, M., Van De Giessen, A. W., Dam-Deisz, W. D. C., Havelaar, A. H., Nagelkerke, N. J. D., \& Henken, A. M. (2004). Risk factors for the presence of Campylobacter spp. in Dutch broiler flocks. Preventive Veterinary Medicine, 62, 35-49. https://doi.org/10.1016/j.prevetmed.2003.09.003.

Bruijnis, M. R. N., Blok, V., Stassen, E. N., \& Gremmen, H. G. J. (2015). Moral "lock-in” in responsible innovation: The ethical and social aspects of killing day-old chicks and its alternatives. Journal of Agricultural and Environmental Ethics, 28, 939-960. https://doi.org/10.1007/s10806-015-9566-7.

Bults, M., Beaujean, D. J., de Zwart, O., Kok, G., van Empelen, P., van Steenbergen, J. E., et al. (2011). Perceived risk, anxiety, and behavioural responses of the general public during the early phase of the Influenza A (H1N1) pandemic in the Netherlands: results of three consecutive online surveys. BMC Public Health, 11, 2. https://doi.org/10.1186/1471-2458-11-2.

CBS Statistics Netherlands. (2018). Landbouw; gewassen, dieren en grondgebruik naar regio. In Landbouw; gewassen, dieren en grondgebruik naar regio. Retrieved from https://opendata.cbs.nl/statl ine/\#/CBS/nl/dataset/80780ned/table?dl=1525B. Accessed 4 Apr 2018.

Childress, J. F., Faden, R. R., Gaare, R. D., Gostin, L. O., Kahn, J., Bonnie, R. J., et al. (2002). Public health ethics: Mapping the terrain. Journal of Law, Medicine and Ethics, 30, 170-178.

Cohen, N. E. (2010). General discussion. In Thesis: Considering animals. Moral convictions concerning animals and judgement on the culling of healthy animals in animal disease epidemics. Wageningen, the Netherlands: Wageningen University.

Cohen, N. E., Brom, F. W. A., \& Stassen, E. N. (2009). Fundamental moral attitudes to animals and their role in judgment: An empirical model to describe fundamental moral attitudes to animals and their role in judgment on the culling of healthy animals during an animal disease epidemic. Journal of Agricultural and Environmental Ethics, 22, 341-359. https://doi.org/10.1007/s10806-009-9157-6.

Cohen, N. E., Brom, F. W. A., \& Stassen, E. N. (2012). Moral convictions and culling animals: A survey in the Netherlands. Anthrozoös, 25, 353-367. https://doi.org/10.2752/175303712x13403555186334.

Cohen, N. E., \& Stassen, E. N. (2016). Public moral convictions about animals in the Netherlands: Culling healthy animals as a moral problem. In F. L. B. Meijboom \& E. N. Stassen (Eds.), The end of animal life: A start for ethical debate. Wageningen: Wageningen Academic publishers.

EFSA. (2011). Scientific Opinion on Campylobacter in broiler meat production: Control options and performance objectives and/or targets at different stages of the food chain. EFSA Journal, 9, 2105. https ://doi.org/10.2903/j.efsa.2011.2105. 
EFSA. (2012). Update of the monitoring of levels of dioxins and PCBs in food and feed. EFSA Journal, 10, 82. https://doi.org/10.2903/j.efsa.2012.2832.

Eurobarometer. (2005). Attitudes of consumers towards the welfare of farmed animals. In Attitudes of consumers towards the welfare of farmed animals Special Eurobarometer. Brussels, Belgium.

Eurobarometer. (2007). Attitudes of consumers towards the welfare of farmed animals. In Attitudes of consumers towards the welfare of farmed animals ed. European Commission, Special Eurobarometer: European Commission.

Evans, A., \& Miele, M. (2008). Consumers' views about farm animal welfare: Part II European comparative report based on focus group research. In Consumers' views about farm animal welfare: Part II European comparative report based on focus group research. Welfare Quality Reports.

Fraser, D. (2003). Assessing animal welfare at the farm and group level: The interplay of science and values. Animal Welfare, 12, 433-443.

Fraser, D., Weary, D. M., Pajor, E. A., \& Milligan, B. N. (1997). A scientific conception of animal welfare that reflects ethical concerns. Animal Welfare, 6, 187-205.

Gocsik, É., Van Der Lans, I. A., Oude Lansink, A. G. J. M., \& Saatkamp, H. W. (2015). Willingness of Dutch broiler and pig farmers to convert to production systems with improved welfare. Animal Welfare, 24, 211-222. https://doi.org/10.7120/09627286.24.2.211.

Gocsik, É., van der Lans, I. A., OudeLansink, A. G. J. M., \& Saatkamp, H. W. (2016). Elicitation of preferences of Dutch broiler and pig farmers to support decision making on animal welfare. NJAS Wageningen Journal of Life Sciences, 76, 75-86. https://doi.org/10.1016/j.njas.2015.11.006.

Gonzales, J. L., Stegeman, J. A., Koch, G., de Wit, S. J., \& Elbers, A. R. W. (2013). Rate of introduction of a low pathogenic avian influenza virus infection in different poultry production sectors in the Netherlands. Influenza and Other Respiratory Viruses, 7, 6-10. https://doi.org/10.111 1/j.1750-2659.2012.00348.x.

Gremmen, B., Bruijnis, M. R. N., Blok, V., \& Stassen, E. N. (2018). A public survey on handling male chicks in the Dutch Egg Sector. Journal of Agricultural and Environmental Ethics. https://doi. org/10.1007/s10806-018-9712-0.

Harvey, D., \& Hubbard, C. (2013). Reconsidering the political economy of farm animal welfare: An anatomy of market failure. Food Policy, 38, 105-114. https://doi.org/10.1016/j.foodpol.2012.11.006.

Heeger, R., \& Brom, F. W. A. (2001). Intrinsic value and direct duties: From animal ethics towards environmental ethics? Journal of Agricultural and Environmental Ethics, 14, 241-252. https://doi. org/10.1023/a:1011319921159.

Heleski, C. R., Mertig, A. G., \& Zanella, A. J. (2006). Stakeholder attitudes toward farm animal welfare. Anthrozoös, 19, 290-307. https://doi.org/10.2752/089279306785415439.

Jensen, K. K., Forsberg, E., Gamborg, C., Millar, K., \& Sandøe, P. (2011). Facilitating ethical reflection among scientists using the ethical matrix. Science and Engineering Ethics, 17, 425-445. https://doi. org/10.1007/s11948-010-9218-2.

Kendall, H. A., Lobao, L. M., \& Sharp, J. S. (2006). Public concern with animal well-being: Place, social structural location, and individual experience. Rural Sociology, 71, 399-428. https://doi. org/10.1526/003601106778070617.

Knight, S., \& Barnett, L. (2008). Justifying attitudes toward animal use: A qualitative study of people's views and beliefs. Anthrozoös, 21, 31-42.

Knight, S., Vrij, A., Bard, K., \& Brandon, D. (2009). Science versus human welfare? Understanding attitudes toward animal use. Journal of Social Issues, 65, 463-483.

Koch, G., \& Elbers, A. R. W. (2006). Outdoor ranging of poultry: A major risk factor for the introduction and development of High-Pathogenicity Avian Influenza. NJAS - Wageningen Journal of Life Sciences, 54, 179-194. https://doi.org/10.1016/s1573-5214(06)80021-7.

Lassen, J., Sandøe, P., \& Forkman, B. (2006). Happy pigs are dirty!-conflicting perspectives on animal welfare. Livestock Science, 103, 221-230. https://doi.org/10.1016/j.livsci.2006.05.008.

McGlone, J. J. (2001). Farm animal welfare in the context of other society issues: Toward sustainable systems. Livestock Production Science, 72, 75-81. https://doi.org/10.1016/S0301-6226(01)00268-8.

Mepham, B. (2000). A framework for the ethical analysis of novel foods: The ethical matrix. Journal of Agricultural and Environmental Ethics, 12, 165-176.

Michalopoulos, T., Korthals, M., \& Hogeveen, H. (2008). Trading "ethical preferences" in the market: Outline of a politically liberal framework for the ethical characterization of foods. Journal of Agricultural and Environmental Ethics, 21, 3-27. 
Musto, M., Faraone, D., \& Cellini, F. (2014). The role of cognitive styles and sociodemographic characteristics in consumer perceptions and attitudes toward nonhuman animal welfare. Journal of Applied Animal Welfare Science, 17, 198-215. https://doi.org/10.1080/10888705.2014.899911.

Rollin, B. E. (1981). Animal rights and human morality. Amherst: Prometheus Books.

Rollin, B. E. (2004). Annual Meeting Keynote Address: Animal agriculture and emerging social ethics for animals. Journal of Animal Science, 82, 955-964.

Rollin, B. E. (2007). Cultural variation, animal welfare and telos. Animal Welfare, 16, 129-133.

Schoeters, G., \& Hoogenboom, R. (2006). Contamination of free-range chicken eggs with dioxins and dioxin-like polychlorinated biphenyls. Molecular Nutrition \& Food Research, 50, 908-914. https:// doi.org/10.1002/mnfr.200500201.

Singer, P. (1995). Animal liberation. London: Random House.

Sommer, H. M., Heuer, O. E., Sørensen, A. I. V., \& Madsen, M. (2013). Analysis of factors important for the occurrence of Campylobacter in Danish broiler flocks. Preventive Veterinary Medicine, 111, 100-111. https://doi.org/10.1016/j.prevetmed.2013.04.004.

Stadig, L. M., Ampe, B. A., Van Gansbeke, S., Van Den Bogaert, T., D’Haenens, E., Heerkens, J. L. T., et al. (2015). Opinion of Belgian egg farmers on hen welfare and its relationship with housing type. Animals, 6, 1-11. https://doi.org/10.3390/ani6010001.

Stadig, L. M., Ampe, B. A., Van Gansbeke, S., Van Den Bogaert, T., D’Haenens, E., Heerkens, J. L. T., et al. (2016). Survey of egg farmers regarding the ban on conventional cages in the EU and their opinion of alternative layer housing systems in Flanders, Belgium. Poultry Science, 95, 715-725. https://doi.org/10.3382/ps/pev334.

Te Velde, H., Aarts, N., \& Van Woerkum, C. (2002). Dealing with ambivalence: Farmers' and consumers' perceptions of animal welfare in livestock breeding. Journal of Agricultural and Environmental Ethics, 15, 203-219. https://doi.org/10.1023/A:1015012403331.

Van Asselt, M., Ekkel, E. D., Kemp, B., \& Stassen, E. N. (2015). Best broiler husbandry system and perceived importance of production aspects by Dutch citizens, poultry farmers and veterinarians. In D. E. Dumitras, I. M. Jitea, \& S. Aerts (Eds.), Know your food. Food ethics and innovation (pp. 138-143). Wageningen: Wageningen Academic Publishers Books. https://doi. org/10.3920/978-90-8686-813-1_20.

Van Asselt, M., Ekkel, E. D., Kemp, B., \& Stassen, E. N. (2017). Citizens perceive broiler welfare differently from poultry farmers and poultry veterinarians. In I. C. De Jong \& P. Koene (Eds.), Citizens perceive broiler welfare differently from poultry farmers and poultry veterinarians, 7th international conference on the assessment of animal welfare at farm and group level, 79. Ede: Wageningen Academic Publishers.

Van Asselt, M., Poortvliet, P. M., Ekkel, E. D., Kemp, B., \& Stassen, E. N. (2018). Risk perceptions of public health and food safety hazards in poultry husbandry by citizens, poultry farmers and poultry veterinarians. Poultry Science, 97, 607-619. https://doi.org/10.3382/ps/pex325.

Vanhonacker, F., Tuyttens, F. A. M., \& Verbeke, W. (2016). Belgian citizens' and broiler producers' perceptions of broiler chicken welfare in Belgium versus Brazil. Poultry Science, 95, 1555-1563. https ://doi.org/10.3382/ps/pew059.

Vanhonacker, F., Verbeke, W., Van Poucke, E., \& Tuyttens, F. A. M. (2008). Do citizens and farmers interpret the concept of farm animal welfare differently? Livestock Science, 116, 126-136. https:// doi.org/10.1016/j.livsci.2007.09.017.

Verbeke, W. (2009). Stakeholder, citizen and consumer interests in farm animal welfare. Animal Welfare, 18, 325-333.

Verhoog, H., Lammerts Van Bueren, E. T., Matze, M., \& Baars, T. (2007). The value of 'naturalness' in organic agriculture. NJAS - Wageningen Journal of Life Sciences, 54, 333-345. https://doi. org/10.1016/S1573-5214(07)80007-8.

Warren, M. A. (1997). Moral status: Obligations to persons and other living things. Oxford: Oxford University Press.

Publisher's Note Springer Nature remains neutral with regard to jurisdictional claims in published maps and institutional affiliations. 


\section{Affiliations}

\section{M. van Asselt ${ }^{1,2}$ (D) E. D. Ekkel ${ }^{3}$ B. Kemp ${ }^{2}$ E. N. Stassen ${ }^{2}$}

1 Aeres University of Applied Sciences Dronten, P.O. Box 374, 8250 AJ Dronten, The Netherlands

2 Adaptation Physiology Group, Department of Animal Sciences, Wageningen University and Research, P.O. Box 338, 6700 AH Wageningen, The Netherlands

3 Aeres University of Applied Sciences Almere, Stadhuisstraat 18, 1315 HC Almere, The Netherlands 